\title{
Behavior of graphitized carbon blacks in the electrodegradation and sorption of chlorophenoxyacetic acids
}

\author{
Stanisław Biniak ${ }^{1}$ - Maciej Pakuła ${ }^{2}$ Andrzej Świątkowski ${ }^{3}$ • \\ Krzysztof Kuśmierek $^{3}$ • Grzegorz Trykowski ${ }^{1}$
}

Received: 5 August 2015/Accepted: 11 October 2015/Published online: 22 October 2015

(C) The Author(s) 2015. This article is published with open access at Springerlink.com

\begin{abstract}
This paper compares the properties of two graphitized carbon blacks in the sorption and first stage of electrodegradation (dechlorination) of chlorophenoxyacetic acids and discusses the influence of surface area on the electrochemical behavior of these carbon materials. Two carbon blacks with ten-fold different surface areas $\left(100\right.$ and $\left.10 \mathrm{~m}^{2} / \mathrm{g}\right)$ were used as sorbents and electrode materials as received. Two chloroorganics with various numbers of $\mathrm{Cl}$ atoms in the molecule, 4-chlorophenoxyacetic acid and 2,4-dichlorophenoxyacetic acid, were adsorbed on the carbon samples from neutral aqueous electrolyte solutions containing low concentrations of adsorbate. Cyclovoltammetric studies of the graphitized carbon blacks were performed using powdered electrode techniques, and the drop in organics concentration during cyclization was measured using HPLC. For carbon black with a smaller surface area, the presence of faradaic reactions was not masked by capacitive currents, and well-shaped faradaic couple peaks characteristic of a quinine/hydroquinone-like adsorbed system were observed. This indicates that these materials are active in chloroorganics electrodegradation (by dechlorination). The extent of electrodegradation (a four-fold drop in organics concentration) observed for carbon black with a larger surface area indicates the dominant role of surface (porosity) development in these processes.
\end{abstract}

Keywords Carbon black · Adsorption - Elecrodegradation · Chlorophenoxyacetic acids

Stanisław Biniak

sbiniak@chem.uni.torun.pl

1 Nicolaus Copernicus University, 87-100 Torun, Poland

2 Naval University of Gdynia, 81-103 Gdynia, Poland

3 Military University of Technology, 00-908 Warsaw, Poland 


\section{Introduction}

Carbon materials are commonly applied as adsorbents, electrode materials, catalysts and catalyst supports in processes that remove pollutants from liquid phases. Poorly biodegradable halogenated organic pollutants such as chlorophenoxyacetic acids (used as herbicides), often present in surface water and sometimes in drinking water, are extremely harmful to human health [1]. Their removal from aquatic environments is at present a topical subject in the literature [2-9]. Adsorption and subsequent electrochemical treatment using various forms of carbon as sorbent and/ or electrode materials for the removal and destruction of these pollutants in aqueous media have been evaluated. A wide variety of carbon electrode materials, such as activated carbon, carbon fibre, carbon black, glassy carbon, graphite, as well as pure and boron-doped diamond have been used for the electro-oxidative removal of chloroorganics in both industrial applications and laboratory studies. Oturan et al. $[6,9]$ studied the initial step of chlorophenoxy herbicide degradation (using electrogenerated Fenton's reagent (EFR)) identifying the polyhydroxyphenols and quinones as intermediates. These products exhibit electrochemical activity and may influence the shape of cyclic voltammograms of powdered carbon electrodes [10]. The high pseudo-capacitive currents in carbon materials, used as electrodes with a well developed porous structure (with a large surface area), mask the relatively smaller faradaic currents, which makes it impossible to gain an understanding of the mechanism of electrode processes.

This paper compares the properties of two graphitized carbon blacks in the sorption and electrodegradation of two chlorophenoxyacetic acids (one of them is commonly used as herbicide) with the aim of describing the influence of surface structure on the electrochemical behavior of carbon electrode materials.

\section{Experimental}

\section{Materials}

Two graphitized carbon blacks (Carbopack B and Carbopack C, Supelco) with tenfold different surface areas (CB-B and CB-C) were used as sorbents and electrode materials as received. The adsorbates and depolarizers (in the electrochemical studies) — two chlorophenoxyacetic acids: 4-chlorophenoxyacetic acid (4-CPA) and 2,4-dichlorophenoxyacetic acid (2,4-DP)—were purchased from Sigma Aldrich.

\section{Porosity and surface area}

The porosity of carbon blacks was characterized by a low-temperature nitrogen adsorption, and the relevant isotherm of the sample was measured at $77.4 \mathrm{~K}$ on a Micromeritics ASAP 2010 volumetric adsorption analyzer (Norcross, GA, USA). Before adsorption measurement, the sample was outgassed under vacuum at $150{ }^{\circ} \mathrm{C}$. 


\section{Raman spectra}

Raman spectra (T-64000 Jobin-Yvon, USA) were collected from 1000 to $2000 \mathrm{~cm}^{-1}$ using a $514.5 \mathrm{~nm}$ excitation laser with a spectral resolution of $2 \mathrm{~cm}^{-1}$. The spectra were deconvoluted and fitted using Lorentzian functions.

\section{Surface oxygen analysis}

An energy dispersive X-ray (EDS) analysis system (Quantax 200, Bruker-AXS Microanalysis, USA), integrated with a scanning electron microscope (SEM, LEO 1430VP, USA), was used to estimate the average oxygen content in the surface layer of the test samples. Six different sites $\left(1 \mathrm{~mm}^{2}\right)$ on the surface of each material were analyzed.

\section{Adsorption}

Chlorophenoxyacetic acids (4-CPA, 2,4-DP) were adsorbed on the carbon black samples $(100 \mathrm{mg})$ at $20{ }^{\circ} \mathrm{C}$ from aqueous electrolyte solutions $\left(100 \mathrm{~cm}^{3} 0.1 \mathrm{M}\right.$ $\mathrm{Na}_{2} \mathrm{SO}_{4}$ ) containing $1 \mathrm{mM}$ concentrations of adsorbate. The initial, partial (for various times) and final (after $6 \mathrm{~h}$ of shaking) concentration of chlorophenoxyacetic acids were measured by HPLC (DAD, Shimadzu LC-20, Kyoto, Japan). The analytes were separated on a Phenomenex Luna $C_{18}(4.6 \times 150 \mathrm{~mm}, 3 \mu \mathrm{m})$ column (Torrance, CA, USA). The chromatographic measurements were carried out under isocratic conditions on a Luna $\mathrm{C}_{18}(4.6 \times 150 \mathrm{~mm}, 3 \mu \mathrm{m})$ column operated at $313 \mathrm{~K}$ with acetononitrile and water adjusted to $\mathrm{pH} 3.0$ with acetic acid (50:50\%, $\mathrm{v} / \mathrm{v})$. The mobile phase was pumped at a flow rate of $0.25 \mathrm{~cm}^{3} \mathrm{~min}^{-1}$, and peaks were monitored at $281 \mathrm{~nm}$.

\section{Cyclovoltammetry}

Electrochemical studies of graphitized carbon black (CB) electrode were performed using cyclic voltammetry in $0.1 \mathrm{M} \mathrm{Na}_{2} \mathrm{SO}_{4}$ as blank electrolyte solutions. After prior vacuum desorption $\left(10^{-2} \mathrm{~Pa}\right.$ ), the powdered graphitic CB (mass $100 \mathrm{mg}$ ) was placed in an electrode container and drenched with a de-aerated solution to obtain a $\sim 5 \mathrm{~mm}$ sedimentation layer. First, the potentiometric responses of the carbon electrode were measured in an oxygen-free atmosphere once its value had stabilized [10]. Next, cyclic voltammetry (CV) was performed using the typical threeelectrode system and an Autolab (Eco Chemie) modular electrochemical system equipped with a PGSTAT 10 potentiostat, driven by GPES3 software (Eco Chemie). All potentials were measured, and are reported against a potassium chloride saturated calomel electrode (SCE). A platinum gauze served as counter electrode. The cyclizations (sweep rate of $5 \mathrm{mV} / \mathrm{s}$ ) always started from zero in the direction of positive potentials. All CV measurements were done between -0.3 and $+1.2 \mathrm{~V}-$ the potential range precluded the electrolysis of water. The first cycle as well as final $\mathrm{CV}$ curves when their shape become reproducible (no change in repeated CV scans) were recorded. 


\section{Infrared spectroscopy}

The FT-IR spectra of the carbon samples initially and after use as electrode materials, were obtained with a Perkin-Elmer FT-IR Spectrum 2000 spectrometer. The carbon-KBr mixtures (1.5:300) were ground, then desorbed at room temperature and pressed to obtain IR-transparent pellets. Following adsorption and electrochemical action, the samples were rinsed in water before pellets formation, dried and desorbed under vacuum at $110{ }^{\circ} \mathrm{C}$.

\section{Results and discussion}

The low-temperature nitrogen adsorption isotherms of the carbon blacks confirm the manufacturer's information about the ten-fold differences in their surface area $\left(\mathrm{S}_{\mathrm{BET}}\right)$ (Table 1). The micro- $\left(\mathrm{V}_{\mathrm{mi}}\right)$ and mesopores $\left(\mathrm{V}_{\mathrm{me}}\right)$ volumes determined using DFT for CB-B were 0.075 and $0.518 \mathrm{~cm}^{3} / \mathrm{g}$, respectively. Despite the low specific area of CB-C, a reliable estimate of its pore size distribution credible estimation was not possible.

The structural details of the carbon blacks were obtained by Raman spectroscopy (Fig. 1). The spectra were collected within the 1000 and $2000 \mathrm{~cm}^{-1}$ range, which

Table 1 Specific surface area $\left(\mathrm{S}_{\mathrm{BET}}\right)$, surface oxygen contents $(\mathrm{O})$ and adsorption abilities $(\mathrm{A})$ towards selected chlorophenoxyacetic acids of graphitized carbon blacks tested

\begin{tabular}{lcccc}
\hline Carbon black & $\mathrm{S}_{\mathrm{BET}}\left(\mathrm{m}^{2} / \mathrm{g}\right)$ & $\mathrm{O} *(\%$ at $)$ & $\mathrm{A}_{4-\mathrm{CPA}}(\mathrm{mmol} / \mathrm{g})$ & $\mathrm{A}_{2,4-\mathrm{D}}(\mathrm{mmol} / \mathrm{g})$ \\
\hline CB-B & $100 \pm 2$ & $3.1 \pm 0.3$ & $0.26 \pm 0.02$ & $0.29 \pm 0.02$ \\
$\mathrm{CB}-\mathrm{C}$ & $10 \pm 1$ & $1.9 \pm 0.3$ & $0.027 \pm 0.005$ & $0.028 \pm 0.005$ \\
\hline
\end{tabular}

\footnotetext{
Surface oxygen from EDS
}

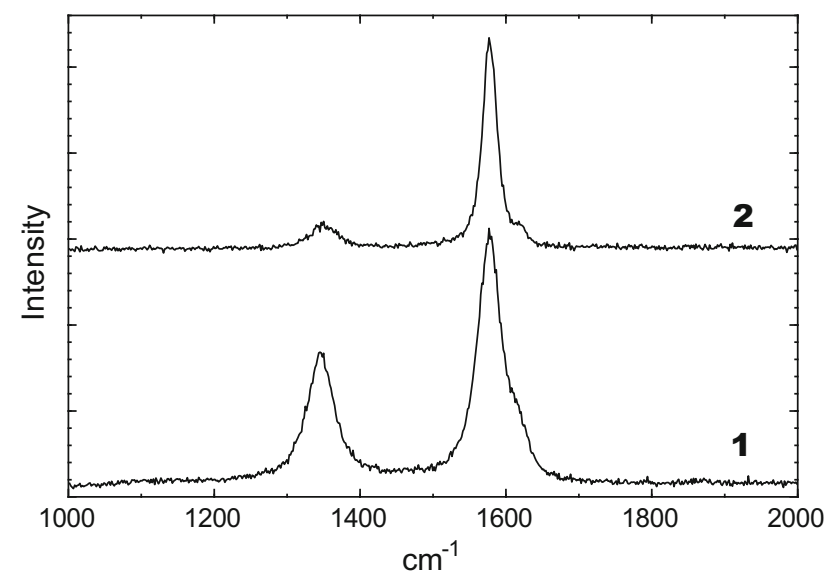

Fig. 1 Raman spectra of carbon blacks: $1-\mathrm{CB}-\mathrm{B}, \mathbf{2}-\mathrm{CB}-\mathrm{C}$ 
corresponds to the wave number range that provides the most valuable data on the structure of carbon materials. Two Raman bands appear at around 1310 and $1600 \mathrm{~cm}^{-1}$. The latter band corresponds to the $\mathrm{E}_{2 \mathrm{~g}}$ mode (stretching vibrations) in the basal graphene layer. The width of this feature is related to the extent of disorder within the plane aromatic layer. The $\mathrm{D}$ band located at $1310 \mathrm{~cm}^{-1}$ is associated with disorder; this forbidden mode becomes active owing to the lack of long-range order in amorphous and quasi-crystalline forms of carbon materials [11]. The width broadens when the sample becomes more amorphous. Comparison of the spectra of the carbon blacks shows that CB-C exhibits much more ordered structure and that the $\mathrm{G}$ bandwidth indicates a greater degree of graphitization.

The ability to adsorb chlorophenoxyacetic acids dissolved in blank electrolyte is different for carbon black of higher specific surface area $\left(S_{B E T}\right.$ near $\left.100 \mathrm{~m}^{2} / \mathrm{g}\right)$ and for material of lower surface area $\left(S_{\mathrm{BET}} \leq 10 \mathrm{~m}^{2} / \mathrm{g}\right)$ (Table 1). According to literature data, the adsorption capacity of chlorine-containing organics generally depends on the number of chlorine atoms in sorbate molecules [12], but with respect to particular chlorophenoxyacetic acids, it depends on the porous structure, surface area, electronic properties and surface chemistry of the carbon materials [13]. The diverse surface structures of the carbon blacks tested explain the differences in the uptake of the chloroorganics $\left(\mathrm{A}_{4-\mathrm{CPA}}, \mathrm{A}_{2.4-\mathrm{D}}\right)$ during their adsorption (Table 1).

Fig. 2 shows cyclic voltammograms of carbon black electrodes recorded in a neutral electrolyte $\left(0.1 \mathrm{M} \mathrm{Na}_{2} \mathrm{SO}_{4}\right)$ solution following stabilization of their shape (final cycles), which takes place after several cycles (dotted lines). The electrochemical behavior of chlorophenoxyacetic acids (as depolarizers) on graphite CB electrodes was studied in neutral electrolyte solutions for a sweep rate of $5 \mathrm{mV} / \mathrm{s}$. In all cases, cyclization was started once the response potential had become stable (until adsorption equilibrium was achieved in $72 \mathrm{~h}$ ). The cyclic voltammograms (first and final) are shown in Fig. 2. The achievement of adsorption equilibrium is presented in Fig. $3 \mathrm{a}-\mathrm{a}$ drop of chlorophenoxic acid in solution was observed under the same conditions as during electrode potential stabilization. Next, potential cyclization was started and continued for $120 \mathrm{~h}$ - the depolarizer concentration decreased throughout this time. For carbon black CB-C (Fig. 3b), there was a slight decrease in the concentration of both target herbicides in electrolyte solution (near $17 \%$ ), but for CBB (Fig. 3b), there was a marked improvement in removal efficiency (4-CPA 50 \%, 2,4-D $\sim 60 \%$ ). The observed differences in the degree of electrodegradation may be due to changes in the surface texture and internal structure of the carbon electrode materials.

The adsorption of both chlorophenoxyacetic acids 4-CPA $\left(\mathrm{A}_{4-\mathrm{CPA}}\right)$ and 2,4-D (A2,4-D) on Carbopack $\mathrm{C}$ is about 10 times less in comparison to Carbopack B (Table 1, Fig. 3a). This is similar to the difference in the specific surface areas of the two carbon blacks. To explain these observations one should take into account not only the specific surface area but also the surface oxygen content (1.9\% at. for Carbopack C, and $3.1 \%$ at. for Carbopack B). For the carbon black with a smaller surface area, the presence of Faradaic reactions was not masked by capacitive currents, and well-shaped faradaic couple peaks characteristic of quinine/hydroquinone-like adsorbed systems were observed (Fig. 2). This indicates that these 
(a)

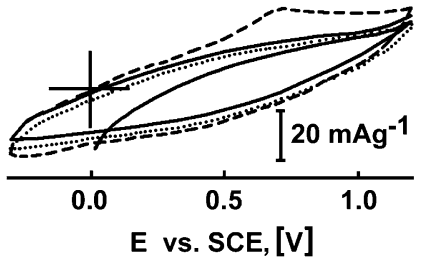

(c)

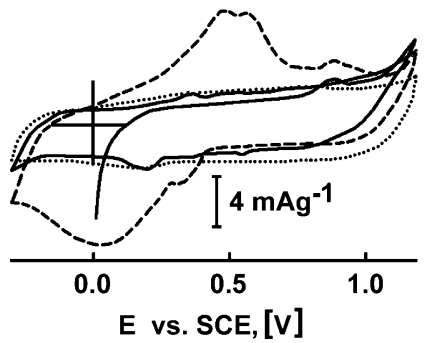

(b)

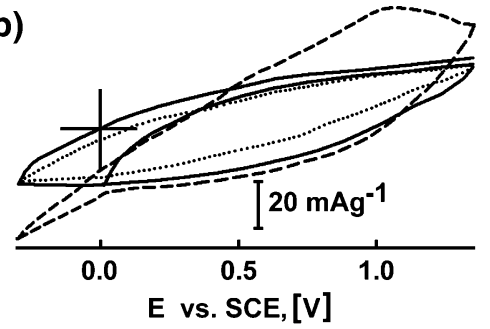

(d)

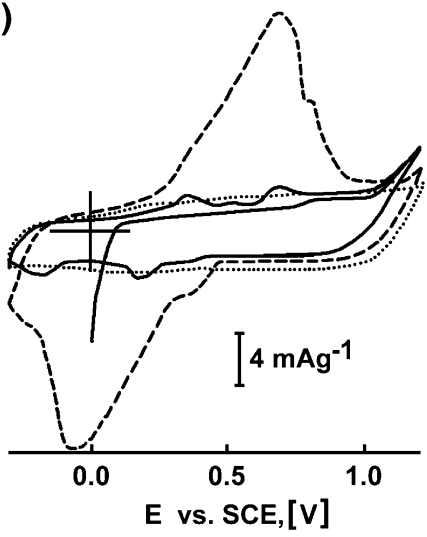

Fig. $2 \mathrm{CV}$ curves for carbon black/chlorophenoxyacetic acids systems in electrolyte solution (0.05 M $\mathrm{Na}_{2} \mathrm{SO}_{4}$ ): (a) CB-B/4-CPA; (b) CB-B/2,4-D; (c) CB-C/4-CPA; (d) CB-C/2,4-D. Seep rate $5 \mathrm{mV} / \mathrm{s}$. Dotted line - blank (0.1 $\mathrm{M} \mathrm{Na}_{2} \mathrm{SO}_{4}$ only); solid line-first cycle, dashed line-final shape of $\mathrm{CV}$ curves. Sweep rate $-5 \mathrm{mV} / \mathrm{s}$

materials are active in the electrodegradation of chloroorganics (by dechlorination). The extent of electrodegradation (a four-fold drop in organics concentration) observed for the carbon black with the larger surface area indicates the dominant role of surface (porosity) structure in these processes. As in the case of chlorophenol electrooxidation, the shape of the $\mathrm{CV}$ curves can be explained the hydrolytic removal of an acetic acid molecule and then by the electooxidation of the chlorophenol unit, which leads to the observed quinone/hydroquinone couple [14]. In the presence of a depolarizer, the course of the CV curves (Fig. 2) in the same blank electrolyte solution changes to an extent dependent on the type of carbon black as the electrode material and the kind of chloroorganic compound.

The FTIR spectra of the initial carbon black samples (Fig. 4 spectra 1) point to differences in their surface chemical structure. It is mainly the $\mathrm{C}-\mathrm{O}-\mathrm{C}$ moiety (structural oxygen) that is observed $\left(1100 \mathrm{~cm}^{-1}\right)$ in the CB-B sample (Fig. 4a)—but several oxygen-containing moieties are present in the CB-C sample (Fig. 4b). There were both similarities and differences in the shapes of the FTIR spectra of the electrode materials following adsorption (Figs. $4 \mathrm{a}$ and $4 \mathrm{~b}$, curves 2 and 3 ) and voltammetric cyclization in neutral $\left(0.1 \mathrm{M} \mathrm{Na}_{2} \mathrm{SO}_{4}\right)$ electrolyte solution (Figs. $4 \mathrm{a}$ and $4 \mathrm{~b}$, curves $2^{\prime}$, $\left.3^{\prime}\right)$ containing chlorophenoxyacetic acids $\left(2,2^{\prime}\right.$ and 3,3'-4-CPA and 2,4-D) as 

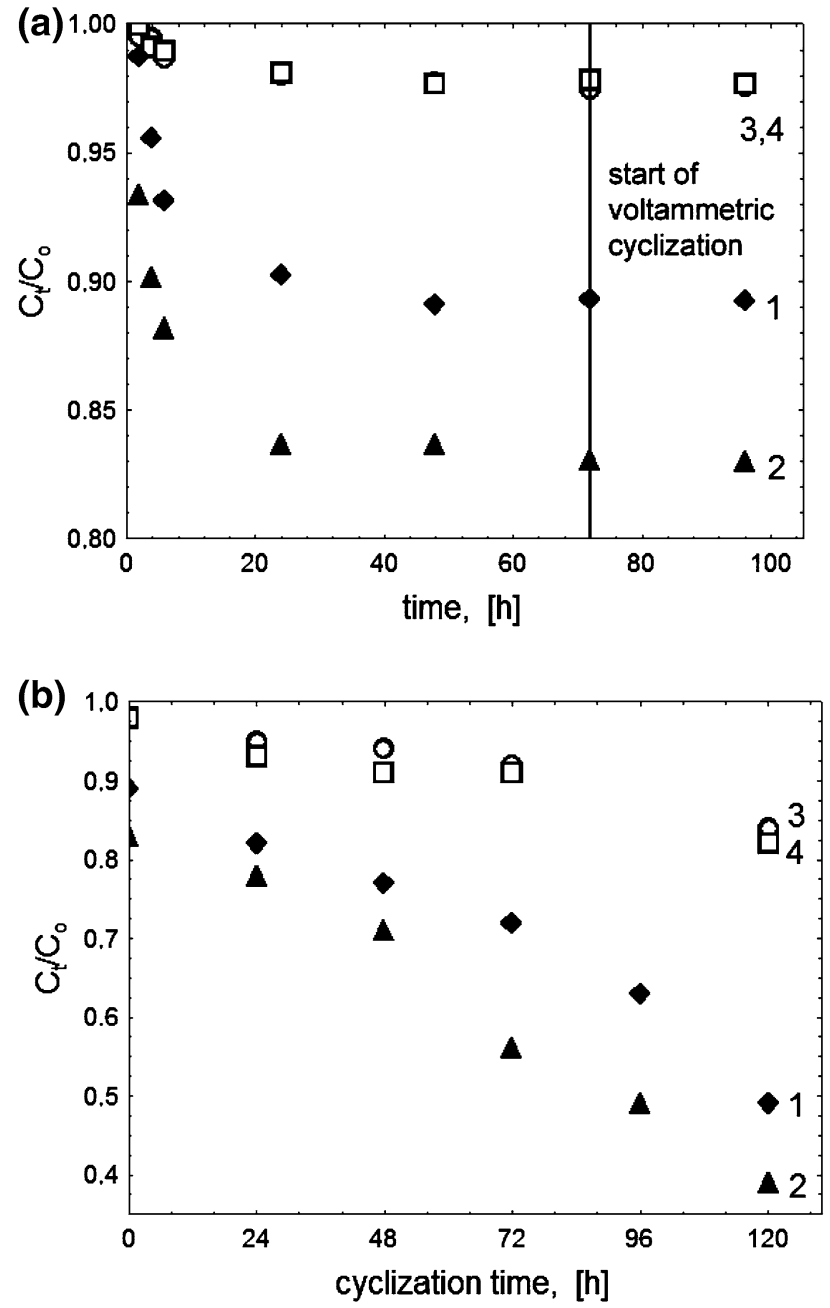

Fig. 3 Concentration drop $\left(\mathrm{C}_{0}=1 \mathrm{mM}\right)$ of 4-CPA $(1,3)$ and 2,4-D $(2,4)$ in blank electrolyte solution: (a) without a slurry agitation (on sediment layer of electrode material); (b) during cyclization time (after $72 \mathrm{~h}$ of adsorption shown in part $(a))$ on carbon black electrodes $(1,2-\mathrm{CB}-\mathrm{B}, 3,4-\mathrm{CB}-\mathrm{C})$

adsorbents and/or depolarizers. The changes in the relative intensity of the main peaks and the appearance of small narrow peaks (e.g. near 1500,1380, $1300 \mathrm{~cm}^{-1}$ and in the $880-700 \mathrm{~cm}^{-1}$ region) due to physically sorbed herbicide depend on the type of carbon blacks, their surface chemistry and porosity. The spectral changes observed after voltammetric cyclization, i.e. a marked increase in the relative intensity of the $1630 \mathrm{~cm}^{-1}$ (quinone-like moieties) and $1440 \mathrm{~cm}^{-1}$ bands (hydroxyl moieties) as well as the overlapping bands in the $1250-950 \mathrm{~cm}^{-1}$ re-gion (carboxylic-phenol esters), may indicate the cleavage of chlorophenols (from the hydrolysis of chlorophenoxyacetic acids) and/or quinone rings on the surface as a consequence of the 
(a)

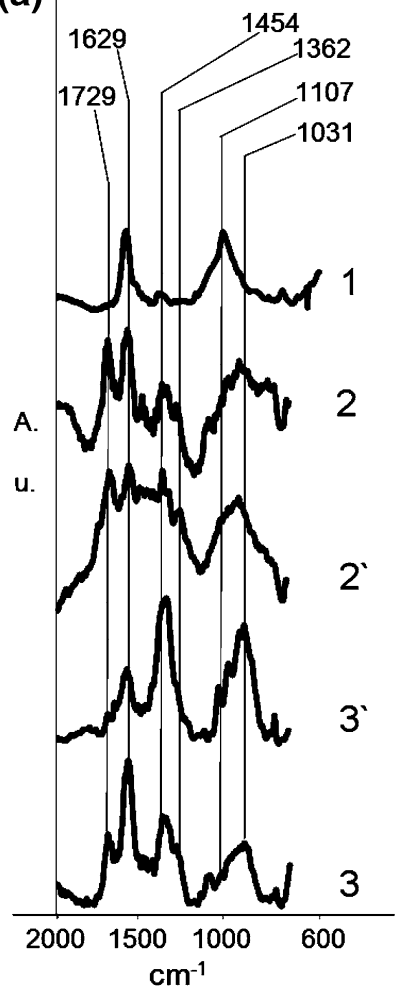

(b)

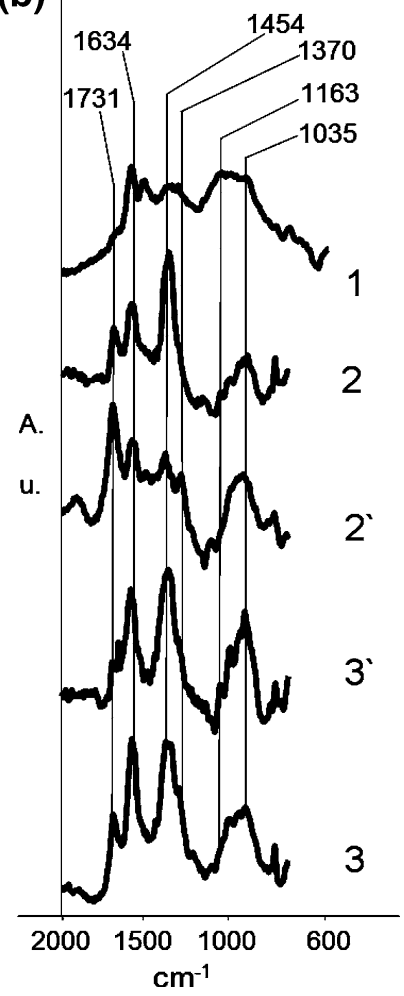

Fig. 4 FTIR spectra of carbon blacks CB-B (a) and CB-C (b): initial (1), after adsorption (2-3) and electrochemical cyclization $\left(2^{\prime}, 3^{\prime}\right)$ from electrolyte solutions containing 4-CPA $\left(2,2^{\prime}\right), 2,4-\mathrm{D}\left(3,3^{\prime}\right)$

electrochemisorption of chlorophenols and electrodegraded herbicide molecules as well as the partial electrochemical ionization and oxidation of chemisorbed species. Additional surface coverage by quinone/hydroquinone-like molecules during voltammetric cyclization probably leads to the observed decrease in the electric double layer (edl) capacity of the carbon black electrodes (see Fig. 2). The shape of the cyclic voltammograms for electrodes from carbon blacks indicates the presence of several anodic and cathodic peaks attributed to redox processes. The steady state peak potentials and currents for (Fig. 2) can be attributed to the reactions of herbicide electrodegradation with quinone-like products [15]:<smiles>O=C1C=CC(=O)C=C1</smiles> 


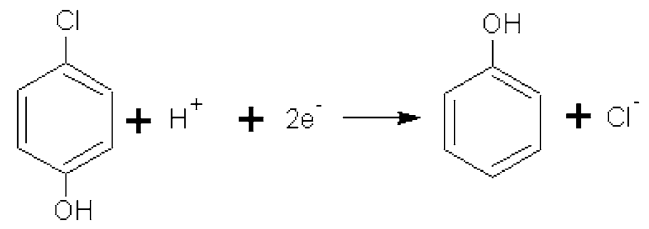

According to the general pathway for the degradation of 4-CPA by anodic oxidation (EFR method) proposed by Boye et al. [16], chlorophenol and quinone/ hydroquinone are create as the result of initial breaking of the lateral chain $(\mathrm{C}(1)-\mathrm{O}$ bond) in herbicide molecules.

\section{Conclusion}

The type and distribution of the porous structure of electrode materials plays a decisive part the initial stages of chlorophenoxyacids electrodegradation on carbon black electrodes. This was confirmed from an interpretation of the FTIR spectral changes in the carbon electrode materials (surface covered by electrodegradation products). The adsorbed quantities of 4-CPA and 2,4-D are about ten-fold greater for carbon black CB-B than CB-C in accordance with the ratio of their surface areas. The ability to remove the pesticides (after $120 \mathrm{~h}$ voltammetric cyclization) turned out to be nearly four times greater for the carbon black with a large surface area than for the low-porous carbon black. The degree of electrodegradation of the target herbicides probably depends on the surface texture and internal structure of the carbon blacks used as electrode materials.

Acknowledgments This work was partially supported by Polish Ministry of Science and Higher Education (Project No. N N209 099037).

Open Access This article is distributed under the terms of the Creative Commons Attribution 4.0 International License (http://creativecommons.org/licenses/by/4.0/), which permits unrestricted use, distribution, and reproduction in any medium, provided you give appropriate credit to the original author(s) and the source, provide a link to the Creative Commons license, and indicate if changes were made.

\section{References}

1. Buchanan I, Liang HC, Liu Z, Razaviarani V (2011) Pesticides and herbicides. Water Environ Res 83:1549-1597

2. Ignatowicz K (2009) Selection of sorbent for removing pesticides during water treatment. J Hazard Mater 169:953-957

3. Derylo-Marczewska A, Blachnio M, Marczewski AW, Swiatkowski A, Tarasiuk B (2010) Adsorption of selected herbicides from aqueous solutions on activated carbon. $\mathrm{J}$ Therm Anal Calorim 101:785-794

4. Pakuła M, Świạtkowski A, Biniak S (2012) Elektroutlenianie chlorofenoksy herbicydów. Badania woltamperometryczne (Electrooxidation of chlorophenoxy herbicides. Voltammetric studies). Przem Chem 91:2413-2415 
5. Brillas E, Boye B, Baños MÁ, Calpe JC, Garrido JA (2003) Electrochemical degradation of chlorophenoxy and chlorobenzoic herbicides in acidic aqueous medium by the peroxi-coagulation method. Chemosphere 51:227-235

6. Oturan N, Sirés I, Oturan MA, Brillas E (2009) Degradation of pesticides in aqueous medium by electro-Fenton and related methods. A review. J Environ Eng Manag 19:235-255

7. Brillas E, Boye B, Sirés I, Garrido JA, Rodríguez RM, Arias C, Cabot PL, Comninellis C (2004) Electrochemical destruction of chlorophenoxy herbicides by anodic oxidation and electro-Fenton using a boron-doped diamond electrode. Electrochim Acta 49:4487-4496

8. Ikehata K, Gamal El-Din M (2006) Aqueous pesticide degradation by hydrogen peroxide/ultraviolet irradiation and Fenton-type advanced oxidation processes:a review. J Environ Eng Sci 5:81-135

9. Oturan MA, Brillas E (2007) Electrochemical advanced oxidation processes (EAOPs) for environmental applications. Port Electrochim Acta 25:1-18

10. Pakuła M, Swiątkowski A, Biniak S (1995) Electrochemical behaviour of modified activated carbons in aqueous and non-aqueous solutions. J Appl Electrochem 25:1038-1044

11. Li ZQ, Lu CJ, Xia ZP, Zhou Y, Luo Z (2007) X-ray diffraction patterns of graphite and turbostratic carbon. Carbon 45:1686-1695

12. Lin P, Zhang Y, Zhang X, Chen Ch, Xie Y, Suffet IH (2015) The influence of chlorinated aromatics' structure on their adsorption characteristics on activated carbon to tackle chemical spills in drinking water source. Front Environ Sci Eng 9:138-146

13. Nyazi K, Baçaoui A, Yaacoubi A, Darmstadt H, Adnot A, Roy Ch (2005) Influence of carbon black surface chemistry on the adsorption of model herbicides from aqueous solution. Carbon 43:2218-2221

14. Biniak S, Swiatkowski A, Pakuła M, Sankowska M, Kuśmierek K, Trykowski G (2013) Cyclic voltammetric and FTIR studies of powdered carbon electrodes in the electrosorption of 4-chlorophenols from aqueous electrolytes. Carbon 51:301-312

15. Biniak S, Pakuła M, Świątkowski A, Kuśmierek K, Trykowski G (2015) Electro-oxidation of chlorophenols on powdered carbon electrodes of different porosity. Reac Kinet Mech Cat 114:369-383

16. Boye B, Dieng MM, Brillas E (2002) Degradation of herbicide 4-chlorophenoxyacetic acid by advanced electrochemical oxidation methods. Environ Sci Technol 36:3030-3035 